\title{
Prevalence of the sick building syndrome symptoms in office workers before and six months and three years after being exposed to a building with an improved ventilation system
}

\author{
Jean Bourbeau, Chantal Brisson, Sylvain Allaire
}

\begin{abstract}
Objective-The prevalence of symptoms associated with the sick building syndrome (SBS) has recently been shown to decrease by $40 \%$ to $50 \%$ among office workers six months after they were exposed to a building with an improved ventilation system. The objective of the present study was to find whether the decrease in the prevalence of symptoms was maintained three years later.

Methods-Workers from the same organisation occupied five buildings in 1991 and moved during that year to a single building with an improved ventilation system. All buildings had sealed windows with mechanical ventilation, air conditioning, and humidification. Workers completed a self administered questionnaire during normal working hours in February 1991 before moving, in February 1992 six months after moving, and in February 1995, three years after moving. The questionnaire encompassed symptoms of the eyes, nose and throat, respiratory system, skin, fatigue, and headache, as well as difficulty concentrating, personal, psychosocial, and workstation factors. During normal office hours of the same weeks, environmental variables were measured.

Results-The study population comprised 1390 workers in 1991,1371 in 1993, and 1359 in 1995, which represents $80 \%$ of the population eligible each year. The prevalence of most symptoms decreased by $40 \%$ to $50 \%$ in 1992 compared with 1991 . This was similar in 1995. These findings were significant and remained generally similar after controlling for personal, psychosocial, and work related factors.

Conclusion-In this study, the decrease of $40 \%$ to $50 \%$ in the prevalence of most symptoms investigated six months after workers were exposed to a new building with an improved ventilation system was maintained three years later. The results of the present follow up study provide further support for a real effect of exposure to a new building with an improved ventilation system on the prevalence of symptoms associated with the SBS.
\end{abstract}

(Occup Environ Med 1997;54:49-53)

Keywords: sick building syndrome; office workers; indoor air quality
From the mid-1970s, there has been increasing awareness of symptoms and complaints experienced in non-industrial buildings. In 1982, a group of experts within the World Health Organisation (WHO) described a multitude of symptoms and perceptions as sick building syndrome (SBS). ${ }^{1}$ This typically involves symptoms from the central nervous system (headache, fatigue, and difficulty concentrating), and from mucous membranes (nose, throat, and airways), eyes, and skin. ${ }^{1}$ Studies selected without regard to symptom complaints reported a prevalence of $20 \%$ or more of at least one work related symptom (usually improving when away from work) among workers occupying office buildings. ${ }^{2-4}$

Although the mechanisms involved in the production of symptoms are largely unknown, in many studies, several factors have been associated with an increased prevalence of symptoms. Personal (allergies and asthma, female sex), psychosocial (stress and dissatisfaction at work), and workstation factors (presence of carpet, time spent at a video display terminal, lighting, noise, comfort) have been associated with an increased prevalence of symptoms. ${ }^{5}$ Building and ventilation factors are thought to influence the prevalence of symptoms associated with the SBS. In a reanalysis of six epidemiological studies, ${ }^{6}$ it was shown that the prevalence of symptoms was consistently two to three times greater in buildings with mechanical ventilation and air conditioning than in buildings with natural or simple mechanical ventilation. In these studies, the presence of sealed windows, in 47 of 48 buildings, was a usual feature of buildings with mechanical ventilation and air conditioning, whereas this feature was present in only five of the 57 buildings with natural or simple mechanical ventilation. Inadequate ventilation is frequent in buildings with SBS problems. ${ }^{7}$ Epidemiological studies, ${ }^{6}$ experimental and non-experimental, have shown increased prevalence of symptoms when the ventilation rate is below $10 \mathrm{l} / \mathrm{s} /$ person $(1 / \mathrm{s} / \mathrm{p})$.

We have recently shown in a natural experiment $^{8}$ that the prevalence of most symptoms associated with the SBS decreased by $40 \%$ to $50 \%$ six months after moving to a building with an improved ventilation system after controlling for personal, psychosocial, and work related factors among office workers. The main objective of the present study was to determine whether the decrease of the prevalence of symptoms was maintained three years later. 
Table 1 Characteristics of the ventilation system in the buildings occupied in 1991 and in the new building with an improved ventilation system occupied in 1992 and 1995

\begin{tabular}{|c|c|c|c|c|}
\hline \multirow[b]{2}{*}{ Characteristic } & \multicolumn{2}{|l|}{ Buildings * occupied in 1991} & \multicolumn{2}{|c|}{$\begin{array}{l}\text { New buildings with an improved } \\
\text { ventilation system }\end{array}$} \\
\hline & Buildings 1 and 2 & Buildings 3 to 5 & Occupied in 1992 & Occupied in 1995 \\
\hline \multicolumn{5}{|l|}{ Ventilation system: } \\
\hline Type of system & HVAC & HVAC & HVAC & HVAC \\
\hline Systems (n) & $\begin{array}{l}\text { Constant air } \\
1 \text { (building 1), }\end{array}$ & $\begin{array}{l}\text { Variable air } \\
1\end{array}$ & $\begin{array}{l}\text { Constant air } \\
9 \text { (with } 30 \text { units }\end{array}$ & $\begin{array}{l}\text { Constant air } \\
9 \text { (with } 30 \text { units }\end{array}$ \\
\hline - & 2 (building 2) & & of distribution) & of distribution) \\
\hline Humidification & $\begin{array}{l}\text { Evaporative (building 1) } \\
\text { Steam (building 2) }\end{array}$ & Evaporative & Steam & Steam \\
\hline Exhaust fan & Present & Absent & Present & Present \\
\hline Filtration & Filters & Filters & Prefilters and filters & Prefilters and filters \\
\hline Capacity of system (CFM) & 40000 to 100000 & Undetermined & 485000 & 485000 \\
\hline \multicolumn{5}{|l|}{ Operation of system: } \\
\hline Time of the day & 24 hours & 0700 to 1800 & $\begin{array}{l}0530 \text { to } 1900 \\
\text { and on demand }\end{array}$ & 0730 to 1700 \\
\hline \multirow{2}{*}{$\begin{array}{c}\text { Outside air intake }(\mathrm{l} / \mathrm{s} / \mathrm{p}) \\
\text { Adjustment threshold of } \\
\text { humidification (\%) }\end{array}$} & $<2 \cdot 4$ & $<2 \cdot 4$ & 28 & 15 \\
\hline & 20 & 20 & 35 & 35 \\
\hline \multicolumn{5}{|l|}{$\begin{array}{l}\text { Air conditioning in } \\
\text { operation at minimum }\end{array}$} \\
\hline \multicolumn{5}{|l|}{$\begin{array}{l}\text { temperature } \\
\text { Maintenance and inspection: }\end{array}$} \\
\hline Filter replacement & $4 \times / y$ & Not done & $4 \times / y$ & $4 \times / y$ \\
\hline Thermostat calibration & $2 \times / y$ & $1 \times / y$ & $2 \times / y$ & $2 \times / y$ \\
\hline Cleaning of system duct & Never & Never & Undetermined & Undetermined \\
\hline
\end{tabular}

HVAC $=$ heating ventilation and air conditioning systems

\section{Methods}

STUDY POPULATION AND BUILDINGS

The eligible population included all workers employed in a large public organisation in Quebec City. Workers occupied five buildings in 1991 and moved during that year to a single building with an improved ventilation system. The five buildings occupied before moving, and the building occupied after, had heating, ventilation, and air conditioning systems, with humidification and sealed windows. The buildings occupied in 1991, built in the 1960 s, had two to 11 floors each, usually covered with carpet. The building occupied in 1992 and 1995 , built in 1991, had three towers of four to six floors, also covered with carpet. Table 1 shows the characteristics of the ventilation systems. The building occupied in 1991 had one or two ventilation systems with an outdoor air intake of less than $2 \cdot 4 \mathrm{1} / \mathrm{s} / \mathrm{p}$, an adjustment threshold of humidification at $20 \%$ and air conditioning in operation at minimum temperatures of $16^{\circ} \mathrm{C}$ and $13^{\circ} \mathrm{C}$. The building occupied from 1992 to 1995 had nine systems and 30 units of distribution with an outdoor air intake of $25-30 \mathrm{l} / \mathrm{s} / \mathrm{p}$ in 1992 and $15-20$ $1 / \mathrm{s} / \mathrm{p}$ in 1995 , an adjustment threshold of humidification at $35 \%$ and air conditioning in operation 12 months of the year. Each half floor was ventilated independently and air from the photocopier rooms was not recirculated. The humidity could be maintained at over $25 \%$ under normal conditions down to an outside temperature of $-28^{\circ} \mathrm{C}$, and the temperature, automatically controlled by numerous probes on each floor, was maintained within the narrow range of 23 to $23.5^{\circ} \mathrm{C}$. The water cleaner in the humidifier did not include biocides. The smoking policy in all the buildings (1991, 1992, and 1995) allowed employees to smoke only in designated areas. However, in the building occupied in 1992 and 1995 , the policy was probably followed more strictly, and air from smoking areas was not recirculated.
COLLECTION OF DATA

Workers completed a self administered questionnaire during working hours in February 1991 before moving, in February 1992 six months after moving, and in February 1995 three years after moving to a new building. February is a winter month in Quebec, with outside temperatures averaging $-10^{\circ} \mathrm{C}$. At that time of the year, workers are mostly confined inside, and outside air supply is likely to be decreased. Questionnaires were completed by each worker at their workplace and were usually returned to the research team the same day. Measurement of environmental variables were conducted during normal office hours in the same week.

\section{QUESTIONNAIRE}

\section{Symptoms}

The questionnaire encompassed seven types of symptoms: eyes (dryness, irritation, or burning), nose and throat (dryness, runny nose, nose congestion), respiratory system (breathlessness, chest tightness, wheezing), skin (dryness, irritation, itching), fatigue, headache, and difficulty concentrating. For each type of symptom, workers were asked whether it ever occurred or not. If so, workers were asked to indicate its frequency (less than once a month, once weekly to once monthly, two to three times weekly, or almost every day) and the place where it occurred (at work only, at work and at home, at home only, others). In the present study, a symptom was operationally defined as occurring only at work two to three times a week or more often.

Factors which may be associated with symptoms A history of respiratory disease was measured with a question inquiring whether workers have ever experienced asthma or chronic pulmonary disease (chronic bronchitis or emphysema). Number of hours at a video display terminal, proximity to a photocopier, and smoking were also assessed by questionnaire. 
Two main components of the psychosocial work environment were measured: job strain, a combination of high psychological job demands and low job decision latitude, and social support at work. ${ }^{9}$ Psychological job demands and job decision latitude were measured with the Karasek 18 item questionnaire. ${ }^{10}$ The French version of this questionnaire has good internal consistency, one year reproducibility, factorial validity, and discriminant validity. ${ }^{11}$ Social support at work was measured with the five item scale recommended in the MONICA psychosocial survey. ${ }^{12}$

Many workstation factors were measured: ambient noise, intensity of lighting, reflected light, comfort at the work station, and workplace intimacy. These factors represent the perception of workers at their workstation and were measured by an adapted version of the tenant survey assessment questionnaire developed by Dillon and Vischer. ${ }^{13}$ The answers for each question were presented on a five point Likert type scale.

\section{Environmental measurements}

In each building, the environmental variables were measured in 1991 and in 1992 on each floor or every other floor and in 1995 on each floor during three days of the same week that the questionnaire was given. Carbon dioxide,

Table 2 Prevalence of symptoms in 1991, 1992, and 1995

\begin{tabular}{llrrr}
\hline & Total workers * & \multicolumn{3}{c}{ Percentage of workers with symptoms } \\
\cline { 3 - 5 } Symptom & $n$ & 1991 & 1992 & 1995 \\
\hline Nose and throat & $1346-59$ & $23 \cdot 0$ & $12 \cdot 4$ & $15 \cdot 2$ \\
Eyes & $1346-52$ & $17 \cdot 1$ & $13 \cdot 6$ & $13 \cdot 7$ \\
Respiratory & $1346-57$ & $3 \cdot 1$ & $1 \cdot 3$ & $1 \cdot 6$ \\
Skin & $1345-50$ & $6 \cdot 9$ & $3 \cdot 2$ & $3 \cdot 0$ \\
Headache & $1353-62$ & $7 \cdot 3$ & $4 \cdot 6$ & $4 \cdot 8$ \\
Difficulty concentrating & $1340-44$ & $18 \cdot 4$ & $18 \cdot 8$ & $15 \cdot 7$ \\
Fatigue & $1338-53$ & $15 \cdot 0$ & $8 \cdot 4$ & $9 \cdot 3$ \\
\hline
\end{tabular}

*Total workers is expressed as a range of values observed over the three phases of the study. Numbers vary across symptoms because of missing values.

Table 3 Psychosocial factors and workstation factors (\%) in the buildings occupied in 1991 and in the building with an approved ventilation system occupied in 1992 and 1995

\begin{tabular}{|c|c|c|c|}
\hline \multirow[b]{2}{*}{ Factors } & \multirow{2}{*}{$\begin{array}{l}\text { Buildings } \\
\text { occupied in } \\
1991\end{array}$} & \multicolumn{2}{|c|}{ Buildings occupied in } \\
\hline & & 1992 & 1995 \\
\hline \multicolumn{4}{|l|}{ Job strain: } \\
\hline Low & $72 \cdot 4$ & $72 \cdot 2$ & $71 \cdot 8$ \\
\hline High & $27 \cdot 6$ & $27 \cdot \overline{8}$ & $28 \cdot 2$ \\
\hline \multicolumn{4}{|l|}{ Social support at work: } \\
\hline High or good & $52 \cdot 8$ & $53 \cdot 5$ & $54 \cdot 4$ \\
\hline Moderate & $27 \cdot 4$ & $26 \cdot 6$ & $28 \cdot 1$ \\
\hline Low & $19 \cdot 8$ & 19.9 & $17 \cdot 5$ \\
\hline \multicolumn{4}{|l|}{ Proximity of a window: } \\
\hline$<3 \mathrm{~m}$. & $62 \cdot 6$ & $38 \cdot 2$ & $40 \cdot 6$ \\
\hline \multicolumn{4}{|l|}{ Time spent at a VDT: } \\
\hline \multicolumn{4}{|l|}{ Ambient noise: } \\
\hline Too noisy & $44 \cdot 0$ & $56 \cdot 4$ & $50 \cdot 7$ \\
\hline Noisy & $32 \cdot 7$ & $20 \cdot 0$ & $22 \cdot 5$ \\
\hline Appropriate & $23 \cdot 3$ & $23 \cdot 6$ & $26 \cdot 8$ \\
\hline \multicolumn{4}{|l|}{ Lighting: } \\
\hline Too bright or glare & $14 \cdot 8$ & $8 \cdot 1$ & $6 \cdot 3$ \\
\hline Not enough & $20 \cdot 5$ & $12 \cdot 5$ & $15 \cdot 0$ \\
\hline Appropriate & $64 \cdot 7$ & $79 \cdot 4$ & $78 \cdot 7$ \\
\hline \multicolumn{4}{|l|}{ Spatial comfort: } \\
\hline Not appropriate & $26 \cdot 9$ & $27 \cdot 1$ & $24 \cdot 5$ \\
\hline Could be improved & $26 \cdot 4$ & 23.5 & $23 \cdot 4$ \\
\hline Appropriate & $46 \cdot 7$ & $49 \cdot 4$ & $52 \cdot 1$ \\
\hline \multicolumn{4}{|l|}{ Workspace cleaning: } \\
\hline Not appropriate & $62 \cdot 3$ & $22 \cdot 5$ & $33 \cdot 8$ \\
\hline Could be improved & $25 \cdot 4$ & 30.9 & 35.9 \\
\hline Appropriate & $12 \cdot 2$ & $46 \cdot 5$ & $30 \cdot 3$ \\
\hline
\end{tabular}

temperature, and relative humidity were measured before working hours and three times during working hours at least at five sites (on the four corners and the centre of the floor) with a portable direct reading instrument. Total volatile organic compounds (VOC), formaldehyde, and total airborne particulates were measured at one site (in the centre of the floor) during working hours. Measurements were made according to the Institut de recherche en santé et en sécurité du travail du Québec (IRSST) ${ }^{14}$ and the American Society of Heating, Refrigerating, and Air-Conditioning Engineers (ASHRAE) standards. ${ }^{15}$

\section{ANALYSIS}

The analysis first involved assessing the crude association between the prevalence of symptoms measured in 1995 and factors associated with symptoms in previous studies. Each type of symptom was analysed separately. The prevalence of symptoms at each level of the factors was compared with the prevalence ratio and its $95 \%$ confidence interval (95\% CI). ${ }^{16}$ The second part of the analysis involved comparing the prevalence of a symptom measured in 1991 with that measured in 1992 and that measured in 1995. The prevalence found in 1991 was used as the reference category. This analysis first involved crude prevalence ratios, prevalence odds ratios, ${ }^{16}$ and $95 \%$ CIs to evaluate comparability of these two effect measures in our data. To control confounding effects of personal, psychosocial, and work related factors, adjusted prevalence odds ratios were obtained by logistic regression. ${ }^{17}$ Data were analysed with the statistical analysis system (SAS). ${ }^{18}$

\section{Results}

After excluding workers on long term leave, on sick leave, and those whose place of work was outside the buildings under study, the eligible population was composed of 1669 workers in 1991, 1717 workers in 1992, and 1677 workers in 1995. After excluding refusals, untraced workers, and those who did not complete the section on symptoms in the questionnaire, 1373 workers were available for study in 1991, 1371 in 1992, and 1359 in 1995 , which represents over $80 \%$ of the population eligible each year.

Table 2 shows the prevalence of symptoms reported by questionnaire in 1995. Difficulty concentrating was the most frequent symptom $(15 \cdot 7 \%)$, followed by symptoms affecting the nose and throat $(15 \cdot 2 \%)$, eyes $(13.7 \%)$, fatigue $(9.3 \%)$, headache $(4.8 \%)$, skin $(3 \cdot 0 \%)$, and respiratory tract $(1 \cdot 6 \%)$.

Table 3 shows psychosocial and workstation factors in the buildings occupied in 1991 and in the building occupied in 1992 and 1995. The reported prevalence of job strain and social support at work were similar in 1991, 1992, and 1995. However, the perception of certain aspects of the workstation changed after moving to the new building in 1992 and 1995. There has been a slight deterioration in ambient noise, an important 
Table 4 Prevalence ratios (PRs) and prevalence odds ratios (PORs) of symptoms in 1992 and 1995 compared with 1991 in all workers*

\begin{tabular}{|c|c|c|c|c|c|c|}
\hline & \multicolumn{2}{|c|}{ PR $(95 \%$ CI) crude analysis } & \multicolumn{2}{|c|}{ POR $(95 \%$ CI) crude analysis } & \multicolumn{2}{|c|}{ POR (95\% CI) adjustedt analysis } \\
\hline & 1992 v 1991 & $1995 v 1991$ & $1992 v 1991$ & 1995 ข 1991 & $1992 v 1991$ & $1995 v 1991$ \\
\hline $\begin{array}{l}\text { Nose and throat } \\
\text { Eyes } \\
\text { Respiratory } \\
\text { Skin } \\
\text { Headache } \\
\text { Fatigue } \\
\text { Difficulty concentrating }\end{array}$ & $\begin{array}{l}0.54(0.45 \text { to } 0.64) \\
0.77(0.65 \text { to } 0.92) \\
0.43(0.25 \text { to } 0.74) \\
0.46(0.32 \text { to } 0.66) \\
0.63(0.46 \text { to } 0.85) \\
0.56(0.45 \text { to } 0.70) \\
1.02(0.87 \text { to } 1.20)\end{array}$ & $\begin{array}{l}0.66(0.57 \text { to } 0.78) \\
0.77(0.65 \text { to } 0.92) \\
0.53(0.32 \text { to } 0.88) \\
0.44(0.31 \text { to } 0.63) \\
0.65(0.48 \text { to } 0.89) \\
0.62(0.50 \text { to } 0.76) \\
0.85(0.72 \text { to } 1.01)\end{array}$ & $\begin{array}{l}0.47(0.38 \text { to } 0.58) \\
0.74(0.60 \text { to } 0.91) \\
0.42(0.24 \text { to } 0.73) \\
0.44(0.31 \text { to } 0.64) \\
0.61(0.44 \text { to } 0.84) \\
0.52(0.41 \text { to } 0.67) \\
1.03(0.85 \text { to } 1.25)\end{array}$ & $\begin{array}{l}0.60(0.50 \text { to } 0.73) \\
0.74(0.60 \text { to } 0.91) \\
0.52(0.31 \text { to } 0.88) \\
0.42(0.29 \text { to } 0.61) \\
0.64(0.46 \text { to } 0.88) \\
0.58(0.46 \text { to } 0.74) \\
0.82(0.67 \text { to } 1.01)\end{array}$ & $\begin{array}{l}0.45(0.35 \text { to } 0.58) \\
0.75(0.59 \text { to } 1.00) \\
0.34(0.17 \text { to } 0.68) \\
0.52(0.34 \text { to } 0.80) \\
0.59(0.40 \text { to } 0.87) \\
0.50(0.37 \text { to } 0.67) \\
0.91(0.72 \text { to } 1.16)\end{array}$ & $\begin{array}{l}0.57(0.46 \text { to } 0.71) \\
0.76(0.60 \text { to } 0.97) \\
0.61(0.34 \text { to } 1.10) \\
0.50(0.33 \text { to } 0.77) \\
0.69(0.48 \text { to } 0.99) \\
0.56(0.43 \text { to } 0.74) \\
0.81(0.64 \text { to } 1.02)\end{array}$ \\
\hline
\end{tabular}

*The numbers of workers were 1373 in 1991,1371 in 1992 and 1359 in 1995

†Adjusted for ambient noise and lighting in the room, comfort at the workstation, comfort of the chair and table, workplace intimacy, smoking, proximity of a window, time spent at a video display terminal, job strain, and social support at work.

improvement of lighting and workspace cleaning and no change in spatial comfort.

Table 4 shows the prevalence ratios and the prevalence odds ratios of symptoms in 1992 and in 1995, six months and three years after moving to the building with an improved ventilation system compared with 1991. In the crude analysis (first and second column), the prevalence of symptoms decreased by $40 \%$ to $50 \%$ in 1992 compared with 1991 and was maintained in 1995 for most symptoms. The decrease in the prevalence of symptoms was similar in 1995 and 1992 for symptoms related to eyes, skin, and for headache. The decrease in the prevalence of symptoms was slightly less in 1995 compared with 1992 for fatigue (6\% less), respiratory tract ( $10 \%$ less), and nose and throat ( $12 \%$ less). The prevalence of difficulty concentrating did not decrease in 1992 or in 1995. Further analyses presented in this table involve prevalence odds ratios. The crude prevalence odds ratios (third and fourth column) were generally similar to the crude prevalence ratios thus indicating the comparability of the two effect measures in our data. The adjusted prevalence odds ratios (fifth and sixth columns) showed that the effect measured remained similar for all except respiratory symptoms, which are rare, when adjusted for personal, psychosocial, and workstation factors. Further analyses involving prevalence odds ratios for 730 workers who completed the questionnaire in 1991, 1992, and 1995 (not shown) yielded similar results.

The figure shows the mean concentrations of $\mathrm{CO}_{2}$, humidity, and temperature in 1991 before moving, in 1992 six months after moving, and in 1995 three years after moving to the building with an improved ventilation system. The concentrations of $\mathrm{CO}_{2}$ presented are the means of the highest daily value at the different sites. The concentrations of $\mathrm{CO}_{2}$ were $810(35.9) \mathrm{ppm}$ in 1991, $598(28.2) \mathrm{ppm}$ in 1992 , and $601(68) \mathrm{ppm}$ in 1995 . The humidity was $22 \%(1.6 \%)$ in $1991,32 \%(0.9 \%)$ in 1992 , and $28 \%(4.6 \%)$ in 1995 . The mean temperatures were comparable in 1991, 1992 , and 1995. The concentrations of total volatile organic compounds, formaldehyde, and total dusts were comparable in 1991, 1992, and 1995 (not shown). They were below $250 \mu \mathrm{g} / \mathrm{m}^{3}$ for total volatile organic compounds, $2 \mu \mathrm{g} / \mathrm{m}^{3}$ for formaldehyde, and $25 \mu \mathrm{g} / \mathrm{m}^{3}$ for total dusts except that $15 \%$ of the total dust samples were $100-150 \mu \mathrm{g} / \mathrm{m}^{3}$ for all three years.

\section{Discussion}

In the present study, the decrease of $40 \%$ to $50 \%$ in the prevalence of most symptoms found six months after workers were exposed to a new building with an improved ventilation system was maintained three years later. This study is one of the rare studies to report a follow up of the prevalence of SBS symptoms in the same population of workers after improvement in the ventilation system.

In the study initially completed in 1992, it could be argued that the workers, not blinded to the change in exposure, were likely to underreport their symptoms six months after moving because of a presumed positive psychological impact of moving to a new building. This was not supported by data on psychosocial factors measured in 1992 . The results of
Mean concentration of $\mathrm{CO}_{2}$, humidity, and temperature in the buildings occupied in 1991, 1992, and 1995.
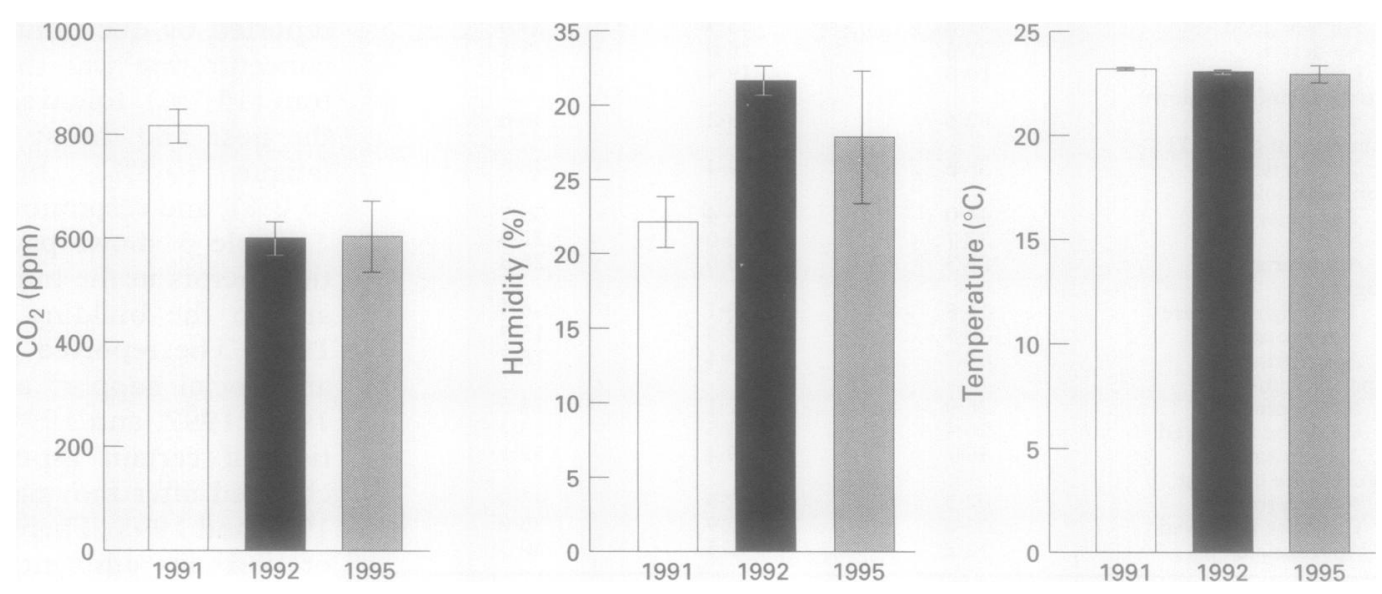
the present follow up study at three years provide further support for a real effect on the prevalence of symptoms of exposure to the new building with an improved ventilation system.

Factors other than the mechanical ventilation system may have changed after moving and could potentially be confounders. ${ }^{5}$ Efforts were made in planning the study to measure potential confounding factors and to control them in the analysis. As for characteristics of the study population such as age, sex, medical factors, and personality, these were inherently controlled by the design. Psychosocial factors are recognised as a potential cause of discomfort. ${ }^{5}$ Job strain, high psychological job demands, low job decision latitude, and low social support at work were measured by questionnaire and were similar in 1991, 1992, and 1995. Workstation factors such as noise, lighting, comfort, proximity of a window, and time spent at a video display terminal are also recognised as potentially associated with SBS symptoms. ${ }^{5}$ Lighting and the proximity of a window improved after moving to the new building. The effects measured remained similar in 1992 and 1995 after controlling for all these psychosocial and workstation factors simultaneously in the multivariate analysis.

Our definition of symptoms required that they be present only at work, as in most studies. Also, our definition required that they be present at least two to three times a week, which we considered more restrictive than in previous studies. This leads to lower prevalence than in previous studies. ${ }^{6}$ However, the order in which the prevalence of most symptoms ranked in our study is consistent with previous studies. ${ }^{6}$

Difficulty concentrating was unchanged after moving to the new building. This symptom was not reported in previous large European studies and the fact that it did not change significantly suggests that it may not be associated with the SBS.

Although this study was not designed to assess specific aetiological exposures, it provides some observations on explanatory factors. In the new building the outdoor air intake decreased from $28 \mathrm{l} / \mathrm{s} / \mathrm{p}$ in 1992 to $15 \mathrm{l} / \mathrm{s} / \mathrm{p}$ in 1995 which is still above the $10 \mathrm{l} / \mathrm{s} / \mathrm{p}$ recommended by ASHRAE ${ }^{15}$ and far above the $2.4 \mathrm{l} / \mathrm{s} / \mathrm{p}$ in 1991 . Our results are consistent with previous studies ${ }^{5}$ which showed a decrease in the prevalence of symptoms when the outdoor air intake improved from below to above $10 \mathrm{l} / \mathrm{s} / \mathrm{p}$. Humidity improved in 1992 and 1995 compared with 1991 and may have contributed to the decrease in the prevalence of symptoms. There was also a more stable temperature in the building occupied in 1992 and 1995. Total volatile organic compounds and formaldehyde were undetectable or at a concentration not known to produce symp- toms. However, these measures were assessed in only a few workstations and may not reflect the variation related to the proximity of specific sources of contamination in the workplace. Contamination from smoking and photocopier machines has, however, been diminished after moving to the new building because air from the smoking areas was not recirculated and photocopier machines were in separate rooms. This could also have contributed to the decreased prevalence of symptoms found in the new building in 1992 and 1995.

We are grateful to the workers who participated in the study. We thank Myrto Mondor and Lyne Des Groseilliers from the Epidemiology Research Group who performed computer analyses and provided statistical advice. We thank Céline Valin for secretarial assistance. This study was funded by the for secretarial assistance. This study was funded by the National Health Research and Development Program of Canada, grant No 6605-3875-58 and the Société de l'Assurance Automobile du Québec (SAAQ). JB is a research scholar supported by Fonds de la Recherche en Santé du Québec. CB is a research scholar supported by the Nationa Health Research and Development Program of Canada. SA is supported by the Québec Public Health Department.

1 World Health Organisation. Guidelines on studies in environmental epidemiology. Geneva: WHO, 1983. (Environmental Health Criteria 27.)

2 Burge S, Hedge A, Wilson S, Bass JH, Robertson A. Sick building syndrome: a study of 4373 office workers. Ann Occup Hyg 1987;31:493-504

3 Skov P, Valbjorn O, Pedersen BV. Influence of indoor climate on the sick building syndrome in an office environment. The Danish Indoor Climate Study Group. Scand $\mathcal{f}$ Work Environ Health 1990;16:363-71.

4 Finnegan J, Pickering CAC, Burge PS. The sick building syndrome: prevalence studies. BMF 1984;289:1573-5.

5 Mendell MJ. Optimizing research on office worker symptoms: recommendations from a critical review of the literature. In: Indoor air 93. Proceeding of the 5th International Conference on Indoor Air Quality and Climate. Helsinki, 1993;1:713-8.

6 Mendell MJ, Smith AH. Consistent pattern of elevated symptoms in air-conditioned office buildings: a reanalysis of epidemiologic studies. Am $\mathcal{F}$ Public Health 1990;80: of epidemi $1193-9$.

7 Samet JM, Marbury MC, Spengler JD. Health effects and sources of indoor air pollution. Part II. Am Rev Respir Dis sources of indoor

8 Bourbeau J, Brisson C, Allaire S. Prevalence of the sick building syndrome symptoms in office workers before and after being exposed to a building with an improved ventilation system. Occup Environ Med 1996;53:204-10.

9 Karasek RA, Theorell T. Healthy work: stress, productivity and the reconstruction of working life. New-York: Basic Books, 1990.

10 Karasek R. Fob content questionnaire and user's guide Department of industrial and systems engineering, University of Southern California, 1985.

11 Brisson C, Moisan J, Vézina M, Vinet A, Dagenais GR C B. Fob strain as a determinant of cardiovascular diseases: validity and reliability of its measurement among 2665 white collar workers. Victoria: International Health Conference, 1992.

12 MONICA-MOPSY. Multinational monitoring of trends and psychosocial determinants in cardiovascular diseases (MONICA)-Monica psychosocial sub-study (MOPSY) Copenhague: Protocole, Organisation mondiale de la santé, Bureau régional de l'Europe, 1987.

13 Dillon R, Vischer JC. Derivation of the tenant questionnair survey assessment method: office building occupant survey data analysis and user manual tenant questionnaire survey. Public Works Canada, 1987.

14 Goyer N, Nguyen VH Stratégie d'étude de la qualité de l'air dans les édifices à bureaux. Montréal, Québec: IRSST, 1989.

15 American Society of Heating Refrigerating and AirConditioning Engineers. Ventilation for acceptable indoor air quality. Atlanta: ASHRAE: 1989.

16 Rothman K. Modern epidemiology. Boston: Little Brown, 1987:35-47,134,153-236.

17 Hosner DW, Lemeshow S. Applied logistic regression. NewYork: John Wiley, 1989 .

18 SAS/STAT. SAS/STAT user's guide, version 6. 4th ed. Cary: SAS Institute, 1990:20. 